\title{
Phylogenetic utility of ribosomal genes for reconstructing the phylogeny of five Chinese satyrine tribes (Lepidoptera, Nymphalidae)
}

\author{
Mingsheng Yang', Yalin Zhang' \\ I Key Laboratory of Plant Protection Resources and Pest Management of Ministry of Education, Entomological \\ Museum, Northwest A\& F University, Yangling, Shaanxi 712100, China \\ Corresponding author: Yalin Zhang (yalinzh@nwsuaf.edu.cn)
}

Academic editor: C. Peña | Received 25 December 2014 | Accepted 5 March 2015 | Published 19 March 2015

http://zoobank.org/89CA4CCB-5244-465A-AEFC-335EAB338C66

Citation: Yang M, Zhang Y (2015) Phylogenetic utility of ribosomal genes for reconstructing the phylogeny of five Chinese satyrine tribes (Lepidoptera, Nymphalidae). ZooKeys 488: 105-120. doi: 10.3897/zookeys.488.9171

\begin{abstract}
Satyrinae is one of twelve subfamilies of the butterfly family Nymphalidae, which currently includes nine tribes. However, phylogenetic relationships among them remain largely unresolved, though different researches have been conducted based on both morphological and molecular data. However, ribosomal genes have never been used in tribe level phylogenetic analyses of Satyrinae. In this study we investigate for the first time the phylogenetic relationships among the tribes Elymniini, Amathusiini, Zetherini and Melanitini which are indicated to be a monophyletic group, and the Satyrini, using two ribosomal genes (28s rDNA and $16 s \mathrm{rDNA}$ ) and four protein-coding genes (EF-1a, COI, COII and Cytb). We mainly aim to assess the phylogenetic informativeness of the ribosomal genes as well as clarify the relationships among different tribes. Our results show the two ribosomal genes generally have the same high phylogenetic informativeness compared with $E F-1 a$; and we infer the $28 s r D N A$ would show better informativeness if the $28 s \mathrm{r} D N A$ sequence data for each sampling taxon are obtained in this study. The placement of the monotypic genus Callarge Leech in Zetherini is confirmed for the first time based on molecular evidence. In addition, our maximum likelihood (ML) and Bayesian inference (BI) trees consistently show that the involved Satyrinae including the Amathusiini is monophyletic with high support values. Although the relationships among the five tribes are identical among $\mathrm{ML}$ and $\mathrm{BI}$ analyses and are mostly strongly-supported in BI analysis, those in ML analysis are lowly- or moderately- supported. Therefore, the relationships among the related five tribes recovered herein need further verification based on more sampling taxa.
\end{abstract}

\section{Keywords}

Butterfly, molecular systematics, Bayesian inference, Satyrinae

Copyright Mingsheng Yang, Yalin Zhang. This is an open access article distributed under the terms of the Creative Commons Attribution License (CC BY 4.0), which permits unrestricted use, distribution, and reproduction in any medium, provided the original author and source are credited. 


\section{Introduction}

The butterfly subfamily Satyrinae, comprising approximately 2,500 described extant species, is amongst the most diverse groups in insects (Ackery et al. 1999). Recently, Marín et al. (2011) summarized the findings of systematic studies on this group (Peña et al. 2006; Peña and Wahlberg 2008; Wahlberg et al. 2009), proposing that the Satyrinae could be divided into nine tribes. However, phylogenetic relationships among them remain mostly unresolved despite they are assigned to four groups (Marín et al. 2011): group one consisting of two Neotropical Morphini and Brassolini; group two including Elymniini, Amathusiini, Zetherini, Dirini and Melanitini; group three including only the Neotropical Haeterini; and group four comprising the speciose Satyrini distributed worldwide. Regarding the group two, phylogenetic relationships of its five tribes remain unresolved except for the well-defined sister relationship of Dirini and Melanitini (Peña et al. 2006; Peña and Wahlberg 2008; Wahlberg et al. 2009; Price et al. 2011; see the figure 1 in Marín et al. 2011). The phylogenetic uncertainty among them can be mainly exhibited in two aspects: one is the weakly supported nodes bearing them; and another is the unstable topologies of trees conducted by different analysis methods (Peña et al. 2006; Peña and Wahlberg 2008; Wahlberg et al. 2009).

It is widely accepted that selecting suitable genetic markers is of great importance in study of molecular systematics. In previous phylogenetic studies on the tribe level relationships of Satyrinae, the protein-coding genes (e.g., mitochondrial COI, and a number of nuclear genes) have been the main source of phylogenetic information (Peña et al. 2006; Peña and Wahlberg 2008; Wahlberg et al. 2009; Price et al. 2011). However, the ribosomal genes, to date have been never considered. The ribosomal genes have already been proven to be informative for phylogenetic analyses in other butterfly groups (e.g., $16 s r D N A$ in Kim et al. 2010; $28 s r D N A$ and $18 s r D N A$ in Jiang et al. 2013).

In order to test the phylogenetic utility of the ribosome genes for constructing the tribe level relationships of Satyrinae which have not been resolved based on morphological and protein-coding sequence data, two ribosomal genes (16s rDNA and $28 \mathrm{~s}$ $r D N A$ ) as well as four additional protein-coding genes (COII, Cytb, COI and EF-1a) are used in our study to reconstruct the phylogeny of the Elymniini, Amathusiini, Zetherini, Melanitini and Satyrini which represent all the major lineages of Chinese satyrines. Besides, we further clarify the taxonomic placement of the Callarge Leech, a satyrine genus which has never been included in previous molecular studies.

\section{Materials and methods}

\section{Taxon sampling}

A total of 30 species were included in the analyses (Table 1). Of these, the 21 in-group species represent all the five satyrine tribes occurring in China. In consideration of 


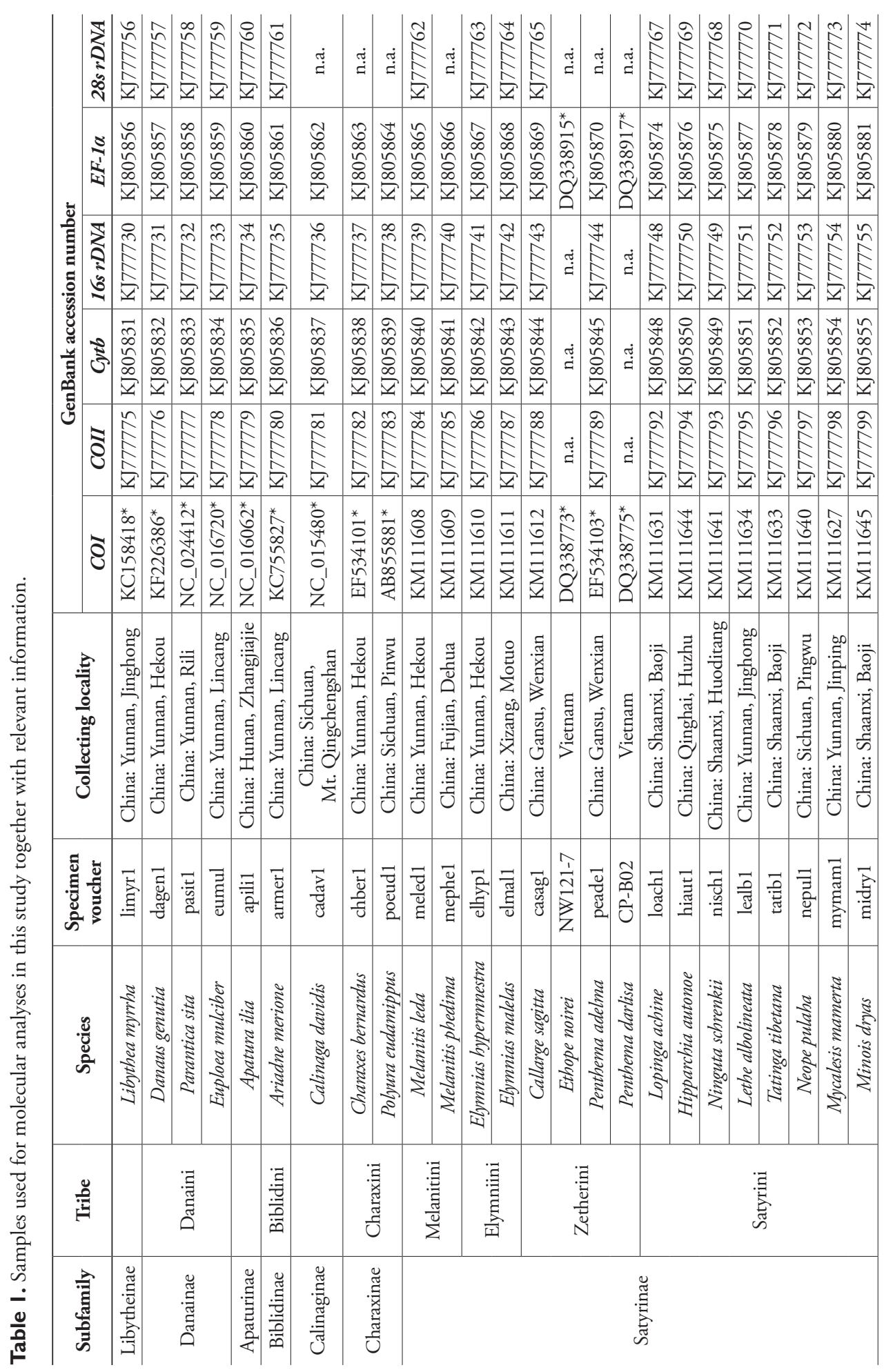




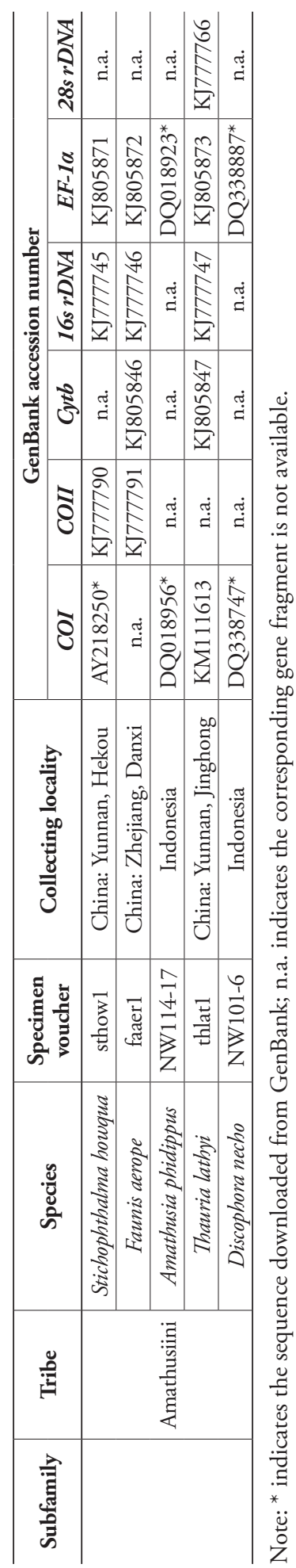


previous studies (Freitas and Brown 2004; Peña et al. 2006), other nine species of six subfamilies (Libytheinae, Danainae, Apaturinae, Biblidinae, Calinaginae and Charaxinae) of the family Nymphalidae were selected as outgroup taxa. Among them, Libythea myrrha Fruhstorfer of Libytheinae was used to root the resulting phylogenetic trees, since Libytheinae is widely accepted as the sister group to the rest Nymphalidae (e.g., Ackery et al. 1999; Freitas and Brown 2004; Peña et al. 2006; Peña and Wahlberg 2008). The butterflies studied stem from the specimens in Entomological Museum of Northwest A\&F University (NWAFU), Yangling, China. Details of the sampling are presented in Table 1.

\section{DNA extraction, amplification and sequencing}

Genomic DNA was extracted from 95-100\% ethanol-preserved muscle tissue of two adult butterfly legs, using an EasyPure Genomic DNA Kit according to the manufacturer's instructions (TransGen Biotech Co., Led., Beijing, China). Extracted genomic DNA was eventually dissolved in $80 \mu \mathrm{L} \mathrm{ddH}_{2} \mathrm{O}$ and kept in a freezer $\left(-20{ }^{\circ} \mathrm{C}\right)$ until it was used for polymerase chain reaction (PCR). Sequences of six nuclear and mitochondrial genes (EF-1a, 28s rDNA, COI, COII, Cytb and 16s rDNA) were amplified through PCR in a total volume of $25 \mu \mathrm{L}$. The volume consisted of $12.5 \mu \mathrm{L} \mathrm{CWBIO} 2$ $\times$ Taq MasterMix, $8.5 \mu \mathrm{L}$ sterile distilled $\mathrm{H}_{2} \mathrm{O}, 2.0 \mu \mathrm{L}$ genomic DNA template and 1.0 $\mu \mathrm{L} 10 \mu \mathrm{M}$ each primer. The primers used and corresponding annealing temperature in PCR as well as references are listed in Table 2. After electrophoretic analysis to ensure the amplification products were the target fragments we needed, the PCR products were subsequently sent to Sunny Biotechnology Co., Ltd. (Shanghai, China) for sequencing with the same primers used in the PCR. All sequences gathered in this study have been deposited in the GenBank.

\section{Sequence analysis and phylogenetic inference}

Sequence chromatogram was checked carefully using Chromas Pro software (Technelysium Pty Ltd., Tewntin, Australia). Each protein-coding sequence was translated for confirmation and assignment of codon positions in Primer Premier version 5.00 software (Premier Biosoft International, Palo Alto, CA). Multiple sequences were aligned using MAFFT version 7.037 with the auto strategy (Katoh and Standley 2013) and, if necessary, manual adjustment was made in MEGA version 6.06 (Tamura et al. 2013). Base frequency and the number of variable and parsimony informative sites were calculated in MEGA version 6.06 (Tamura et al. 2013). We investigated the chi-square of homogeneity of base frequencies across taxa for each gene with the program PAUP4.0b10 (Swofford 2002). The aligned ambiguous regions of two non-coding ribosomal genes (i.e. $16 s \mathrm{~s} D N A$ and $28 s \mathrm{~s} D N A$ ) were retained because these positions might contain some information that is potentially useful 
Table 2. Primers in PCRs for multiple genes used in this study.

\begin{tabular}{|c|c|c|c|c|}
\hline Gene & $\begin{array}{c}\text { Primer name (forward } \\
\text { or reverse reading) }\end{array}$ & Sequence & \begin{tabular}{|c|} 
Annealing \\
temperature
\end{tabular} & References \\
\hline \multirow{2}{*}{ COI } & LCO1490 (f) & GGT CAA CAA ATC ATA AAG ATA TTG G & \multirow{2}{*}{$51^{\circ} \mathrm{C}$} & $\begin{array}{l}\text { Folmer et al. } \\
\text { (1994) }\end{array}$ \\
\hline & HCO2198 (r) & TAA ACT TCA GGG TGA CCA AAA AAT CA & & $\begin{array}{l}\text { Folmer et al. } \\
\text { (1994) }\end{array}$ \\
\hline \multirow{2}{*}{ COII } & EVA (f) & GAG ACC ATT ACT TGC TTT CAG TCA CT & \multirow{2}{*}{$53^{\circ} \mathrm{C}$} & $\begin{array}{c}\text { Caterino and } \\
\text { Sperling (1999) }\end{array}$ \\
\hline & PATRICK (r) & CTA ATA TGG CAG ATT ATA TGT ATT GG & & \begin{tabular}{|c|} 
Caterino and \\
Sperling (1999)
\end{tabular} \\
\hline \multirow{2}{*}{ Cytb } & CB-N3665 (f) & GTC CTA CCA TGA GGT CAA ATA TC & \multirow{2}{*}{$50^{\circ} \mathrm{C}$} & $\begin{array}{c}\text { Simon et al. } \\
(2006)\end{array}$ \\
\hline & CB-N11526 (r) & TTC AAC TGG TCG TGC TCC AAT TCA & & $\begin{array}{c}\text { Simon et al. } \\
(2006)\end{array}$ \\
\hline \multirow{2}{*}{$16 r \mathrm{rDNA}$} & LR-J-12887 (f) & CCG GTT TGA ACT CAG ATC ACG T & \multirow{2}{*}{$49^{\circ} \mathrm{C}$} & $\begin{array}{c}\text { Simon et al. } \\
(1994)\end{array}$ \\
\hline & LR-N-13398 (r) & CGC CTG TTT ATC AAA AAC AT & & $\begin{array}{l}\text { Simon et al. } \\
(1994)\end{array}$ \\
\hline \multirow{3}{*}{$E F-1 a$} & ELF2F (f) & AAA ATG CCC TGG TTC AAG GGA & \multirow{3}{*}{$52^{\circ} \mathrm{C}-57^{\circ} \mathrm{C}$} & $\begin{array}{l}\text { Wan et al. } \\
(2013)\end{array}$ \\
\hline & ef51.9 (f) & CAR GAC GTA TAC AAA ATC GG & & $\begin{array}{l}\text { Monteiro and } \\
\text { Pierce (2001) }\end{array}$ \\
\hline & efrcM4 (r) & ACA GCV ACK GTYTGY CTC ATR TC & & $\begin{array}{l}\text { Monteiro and } \\
\text { Pierce (2001) }\end{array}$ \\
\hline \multirow{2}{*}{$28 s \mathrm{rDNA}$} & rD3.2a (f) & AGT ACG TGA AAC CGT TCA SGG GT & \multirow{2}{*}{$58.8^{\circ} \mathrm{C}$} & $\begin{array}{l}\text { Whiting } \\
(2002)\end{array}$ \\
\hline & Rd4.2b (r) & CCT TGG TCC GTG TTT CAA GAC GG & & $\begin{array}{l}\text { Whiting } \\
(2002)\end{array}$ \\
\hline
\end{tabular}

for phylogenetic reconstruction (Aagesen 2004; Redelings and Suchard 2009). As proposed by Xia et al. (2003), we performed tests of substitutional saturation based on the Iss (i.e. index of substitutional saturation) statistic for different partitioned dataset with DAMBE version 5.3.74 (Xia 2013). For this method, if Iss is smaller than Iss.c (i.e. critical Iss), we can infer that the sequences have experienced little substitutional saturation (Xia and Lemey 2009).

Maximum likelihood (ML) analysis was performed using the raxmlGUI version 1.3 interface (Silvestro and Michalak 2012) of RAxML version 7.2.6 (Stamatakis 2006). The best-fit substitution model for each gene partition was determined by jModelTest version 2.1.4 (Darriba et al. 2012) under the Akaike Information Criterion (AIC) (Akaike 1974). Clade supports were assessed using the $\mathrm{ML}+$ rapid bootstrap algorithm with 1000 bootstrap iterations.

Bayesian inference (BI) analyses were conducted in MrBayes 3.1.2 (Ronquist and Huelsenbeck 2003). The best-fit partitioning schemes and partition-specific substitution models, defined from 16 subsets formed by gene and codon position of the six genes used, were tested using the 'greed' algorithm of program PartitionFinder v1.1 
(Lanfear et al. 2012) under the Bayesian information criterion (BIC). Two independent MCMC runs were performed either for 300,000 generations or until the average standard deviation of split frequencies fell below 0.01 . The sampling frequency was set as every 100 generations. After the first $25 \%$ of the yielded trees were discarded as burn-in, a $50 \%$ majority-rule consensus tree with the posterior probability (PP) values was constructed by summarizing the remaining trees. For BI analyses, two different datasets, the full six-gene-dataset and the non-COI + Cytb + COII-3rds-dataset (with 3rd positions removed), were used to examine the phylogenetic utility of the 3rd sites of $\mathrm{COI}+\mathrm{Cytb}+\mathrm{COII}$, because these sites have suffered substantial saturation (see the results).

\section{Phylogenetic informativeness}

We used phylogenetic informativeness (PI) profiles to quantify the relative contribution of each partition to the resulted tree. The peak of the PI distribution is suggested to predict the maximum phylogenetic informativeness for corresponding partition (Owen et al. 2014). The PI profiles were generated with the PhyDesign (Townsend 2007; Lopez-Giraldez and Townsend 2011). For this, the aligned sequences and an ultrametric tree are needed as input files. In the sequence file, the eight partition schemes identified by PartitionFinder v1.1 (Lanfear et al. 2012) were applied. The ultrametric tree was generated with the BEAST version 1.7.5 (Drummond et al. 2012) using the eight partitions and corresponding models determined by PartitionFinder v1.1 (Lanfear et al. 2012) as well.

\section{Results}

\section{Sequence characterization}

One hundred and fifty-four sequences of the six genes were obtained for 30 species (Tables 1, 3). The final alignment yields $3,402 \mathrm{bp}$ of the combined sequence data, of which 1,312 are variable and 1,053 are parsimony informative. The Chi-square test reveals no significant base composition heterogeneity among the taxa for any gene fragment, even for the 28s $r D N A$ showing a high level of CG base composition $(p=0.138)$. In the case of the saturation test, all observed values of Iss are smaller than the Iss.c values for both symmetrical and asymmetrical topologies in all gene fragments. However, when the analysis was taken for each of the three codon positions of coding gene fragments separately, values of Iss for the third codons of all the COI, COII and Cytb genes are smaller than the Iss.c values in both symmetrical and asymmetrical topologies, indicating some of these sites have suffered substantial saturation. 
Table 3. Sequence statistics for the six gene regions.

\begin{tabular}{c|c|c|c|c|c|c}
\hline & COI & COII & Cytb & 16s $\boldsymbol{r D N A}$ & $\boldsymbol{E F}$-1a & 28s $\boldsymbol{r D N A}$ \\
\hline Number of sequences & 29 & 25 & 25 & 26 & 30 & 19 \\
\hline Alignment length (bp) & 621 & 690 & 591 & 530 & 510 & 460 \\
\hline Percentage A(\%) & 29.6 & 34.9 & 31.7 & 37.7 & 25.5 & 15.5 \\
\hline Percentage T(\%) & 39.5 & 41.6 & 43.3 & 41.6 & 26.1 & 18.2 \\
\hline Percentage C(\%) & 16.7 & 13.4 & 16.0 & 12.8 & 25.9 & 33.8 \\
\hline Percentage G(\%) & 14.2 & 10.1 & 9.0 & 7.9 & 22.5 & 32.5 \\
\hline Number of variable sites & 233 & 288 & 275 & 167 & 165 & 184 \\
\hline $\begin{array}{c}\text { Number of parsimony } \\
\text { informative sites }\end{array}$ & 203 & 222 & 226 & 125 & 139 & 138 \\
\hline $\begin{array}{c}\text { Chi-square test of base } \\
\text { frequency }\end{array}$ & $p=1.000$ & $p=1.000$ & $p=0.998$ & $p=1.000$ & $p=0.999$ & $p=0.138$ \\
\hline
\end{tabular}

Table 4. The best-fit partitioning schemes and corresponding partition models used in BI analysis.

\begin{tabular}{|c|c|c|}
\hline Partitioned dataset & $\begin{array}{c}\text { Nucleotide model } \\
\text { under BIC }\end{array}$ & $\begin{array}{c}\text { Implemented parameters in } \\
\text { BI analysis }\end{array}$ \\
\hline 1) $C O I 1 \mathrm{st}+C O I I 1 \mathrm{st}+$ Cytb 1st & $\mathrm{GTR}+\mathrm{I}+\mathrm{G}$ & $\mathrm{nst}=6$, rates $=$ invgamma \\
\hline 2) $C O I$ 2nd + COII 2nd + Cytb 2nd & $\mathrm{HKY}+\mathrm{I}+\mathrm{G}$ & $\mathrm{nst}=2$, rates $=$ invgamma \\
\hline 3) $C O I 3 \mathrm{rd}+\mathrm{COII} 3 \mathrm{rd}+$ Cytb 3rd & $\mathrm{HKY}+\mathrm{G}$ & nst $=2$, rates $=$ gamma \\
\hline 4) $16 s r D N A$ & $\mathrm{GTR}+\mathrm{I}+\mathrm{G}$ & $\mathrm{nst}=6$, rates $=$ invgamma \\
\hline 5) $28 s r D N A$ & $\mathrm{GTR}+\mathrm{G}$ & nst $=6$, rates $=$ gamma \\
\hline 6) $E F-1 a 1 \mathrm{st}$ & $\operatorname{TrN}+\mathrm{I}$ & $\mathrm{nst}=6$, rates $=\mathrm{inv}$ \\
\hline 7) $E F-1 a$ 2nd & JC & $\mathrm{nst}=1$ \\
\hline 8) $E F-1 a 3 \mathrm{rd}$ & $\mathrm{GTR}+\mathrm{G}$ & nst $=6$, rates $=$ gamma \\
\hline
\end{tabular}

\section{Model selection and phylogenetic reconstruction}

Each gene partition shows the GTR $+\mathrm{I}+\mathrm{G}$ for its best-fit substitution model except the $28 s r D N A$ being the GTR + G, but we imposed the GTR + G for all gene partitions in ML analysis as recommended by Zahiri et al. (2011). For BI analysis, the best partitioning scheme includes eight partitions. Each partition and corresponding parameters used in BI analyses are summarized in Table 4.

The ML and BI trees based on the full six-gene-dataset show generally identical topologies (summarized in Figure 1). All tribes included with two or more taxa examined in this study are recovered to be monophyletic mostly with strong support values. The traditional "satyrine" clade consisting of Calinaginae, Charaxinae and Satyrinae is well-recovered by strong bootstrap value (BV) 100 and PP 1.00. The five tribes of Chinese satyrines constitute the Satyrinae clade with BV 93 and PP 1.00. Within this clade, the Satyrini is consistently recovered as sister of others. Then, Amathusiini branches off, and the Zetherini is sister to the sister group (Melanitini + Elymniini), but the relationship between Melanitini and Elymniini is poorly supported by both $\mathrm{ML}$ and $\mathrm{BI}$ analyses $(\mathrm{BV}=42, \mathrm{PP}=0.71)$. The genus Callarge is nested into the Zetherini, forming a sister group with Penthema Westwood. 


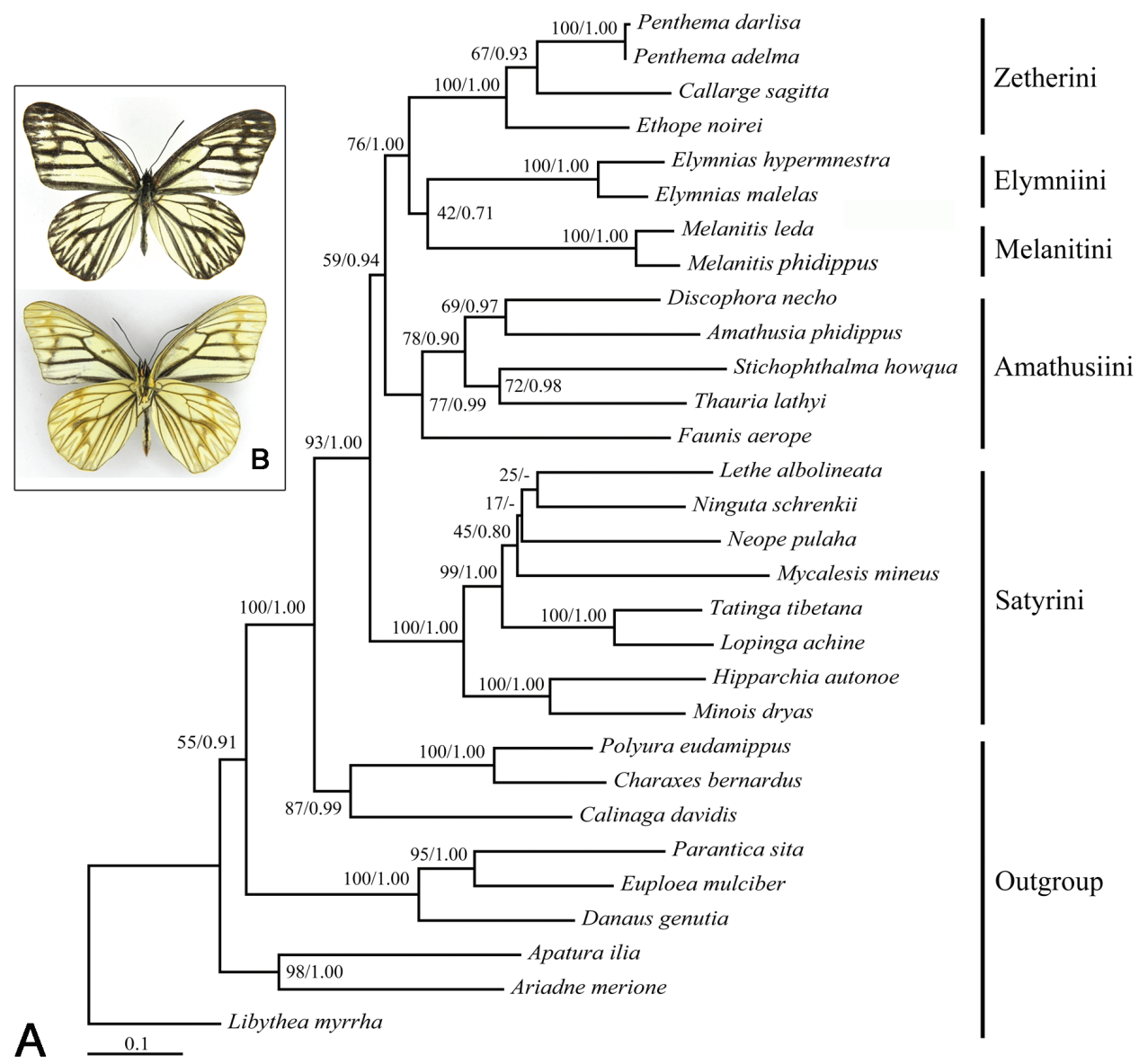

Figure I. A Bipartitions tree obtained from maximum likelihood (ML) analysis based on the full sixgene-dataset; numbers separated by a slash on node are bootstrap value (BV) and posterior probability (PP) B Callarge sagitta (Leech), habitus, dorsal view on the above and ventral view on the below.

The trees constructed based on the non-COI + Cytb + COII-3rds-dataset is shown in Figure 2. The tree shows generally same topology with that based on the full six-genedataset, but some nodes especially that describing the terminal taxa are less resolved. This indicates that the 3 rd sites of $C O I+C y t b+C O I I$ provided poor supports for the tribe level relationships.

\section{Phylogenetic informativeness}

As shown in Figure 3, the 3rd codon positions of the combined COI, Cytb and COII has the highest phylogenetic signal at all taxonomic levels, and a peak of the PI distribution can be recognized at about the $1 / 3$ position of the tree near the terminal branches. Followed are the 1st codon positions of the combined COI, Cytb and COII. 


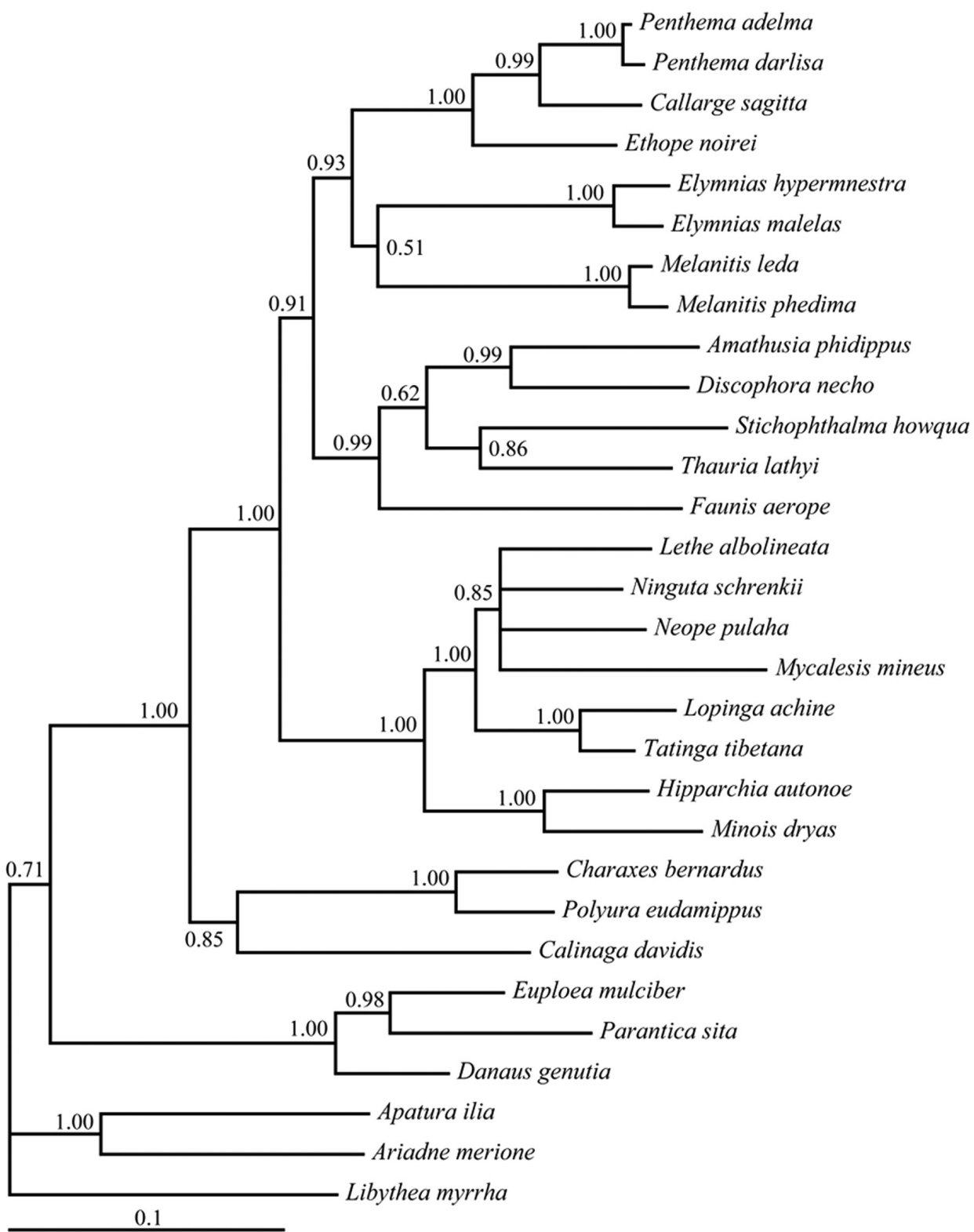

Figure 2. 50\% majority-rule trees obtained from Bayesian inference $(\mathrm{BI})$ analyses based on the non-COI $+C y t b+C O I I-3 r d s-d a t a s e t$. Numbers on nodes are the posterior probabilities (PP).

The ribosomal $16 s$ and $28 s$ DNA generally show the same phylogenetic informativeness with the 3rd codon positions of EF-1a, especially on the zone of tree showing the tribe level relationships of the Satyrinae. The remaining 2nd codon positions of the combined COI, Cytb and COII, the 1st and 2nd codon positions of EF-1a show relatively limited phylogenetic signals. 


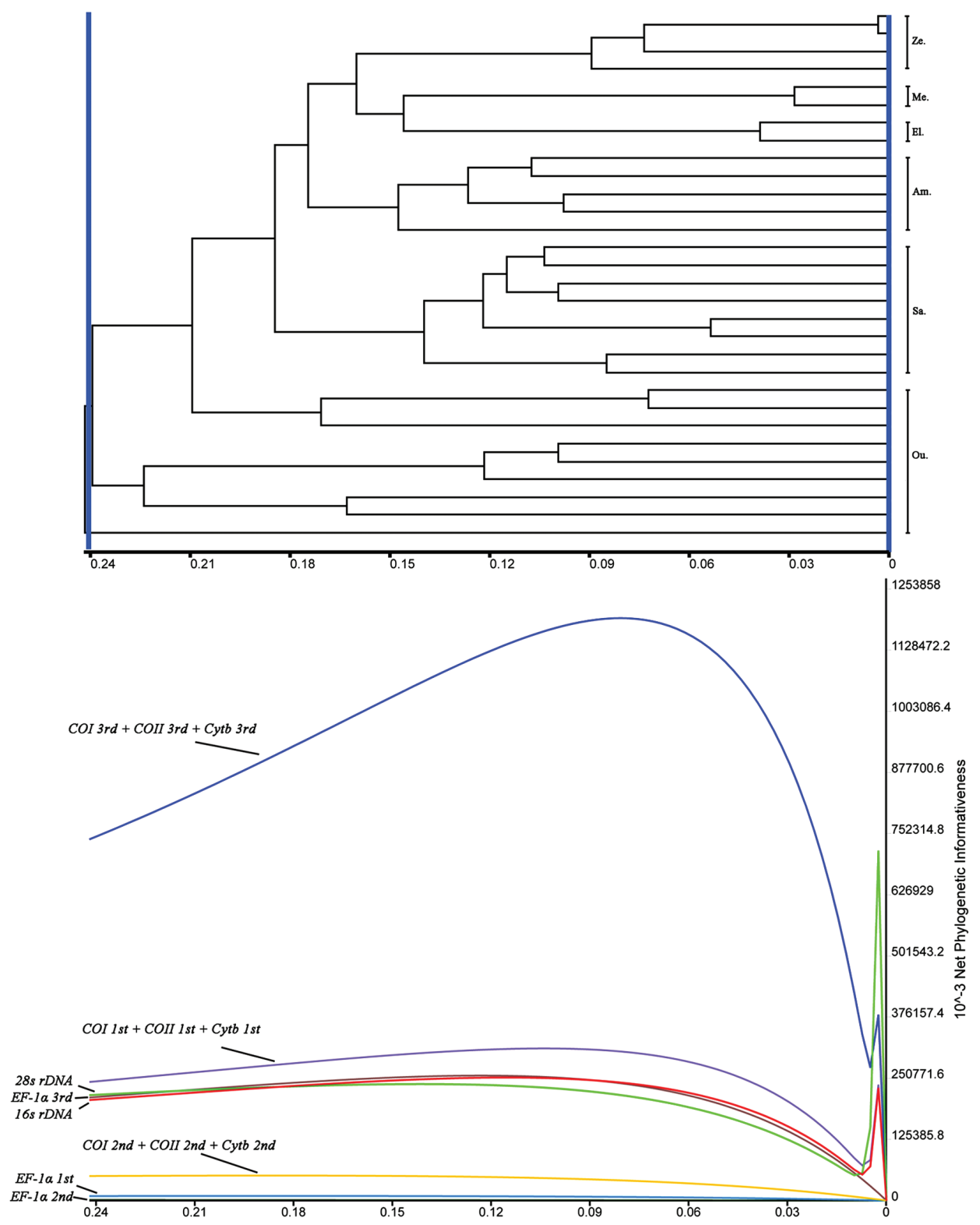

Figure 3. Phylogenetic informative profiles for all subsets used in this study. Ze. Zetherini; El. Elymniini; Me. Melanitini; Am. Amathusini; Sa. Satyrini.

\section{Discussion}

\section{Phylogenetic informativeness of related genes}

The studies of molecular systematics have been increasingly accessible because more genetic markers have been developed with the advances of sequencing technology. 
However, how to make informed choice to these markers confuses many systematics (Danforth et al. 2005). In high level systematics of Satyrinae, EF-1a was commonly used and proven to be quite informative in all previous studies (Peña et al. 2006; Peña and Wahlberg 2008; Wahlberg et al. 2009). Our results show the two ribosomal genes (i.e. $16 s r D N A$ and $28 s r D N A$ ) have generally the same phylogenetic informativeness with EF-1a (Figure 3), which indicates that the former two genes also contribute well in constructing the tribe level relationships. Moreover, we infer the $28 \mathrm{~s} r N A$ would show better informativeness if the 28s $r D N A$ sequence data for each sampling taxon had been obtained in this study. The consistency between the 28s rDNA and EF-1a in phylogenetic utility supports the findings of Danforth et al. (2005) who suggested that the nuclear ribosomal and protein-coding genes should be combined in phylogenetic practices after comparing the substitution patterns between them in other groups of insects. The $16 s r D N A$ have been proven to be informative in high level systematics (e.g. Nazari et al. 2007) and was even recommended as standard marker for insect phylogenetics (Caterino et al. 2000). The high phylogenetic utility of $16 \mathrm{~s} r D N A$ examined in this study provides support for these proposals. However, this result does not support that mitochondrial gene datasets should not be applied on the deep divergences due to their substantial variation (Lin and Danforth 2004; Danforth et al. 2005).

We do not recommend the use of the 3rd positions of combined COI, Cytb and COII in high level systematics of Satyrinae, although these sites show higher phylogenetic signals than other partitions (Figure 3). On the one hand, our saturation tests show some sites of the 3rd positions of combined COI, Cytb and COII have suffered substantial saturation. These sites may positively contribute to the tip nodes of trees, but for the nodes after the PI profile peak they may become the source of noise deep in the tree and cause homoplasy (Owen et al. 2014). On the other hand, the deep branch pattern of BI tree (Figure 2) generally not change when excluding the 3rd positions of combined COI, Cytb and COII. This result indicates that the $3 \mathrm{rd}$ positions of combined COI, Cytb and COII contribute poorly to the tribe level relationships of the trees based on the full six-gene-dataset.

\section{Phylogenetic relationships among related tribes of Satyrinae}

In this study, we present the first use of the ribosomal genes in reconstructing the tribe level relationships of the Satyrinae. The "satyrine" clade consisting of Calinaginae, Charaxinae and Satyrinae defined by Peña and Wahlberg (2008) and Wahlberg et al. (2009) are well-supported by our results. Moreover, monophyly of involved Satyrinae with the Amathusiini included is highly supported by all ML and BI analyses based on multiple outgroup taxa, which confirms, at least partially, the findings of Peña et al. (2006) who noted Satyrinae is monophyletic with inclusion of the tribes Morphini, Brassolini and Amathusiini of Morphinae (sensu Ackery et al. 1999) (Peña and Wahlberg 2008; Wahlberg et al. 2009). 
Among the five tribes of Satyrinae analyzed, our results recover the Satyrini as the basal lineage with a long-branch split from the rest four tribes, in agreement with the findings of Peña et al. (2006) and Peña and Wahlberg (2008). However, relationships among the remaining four tribes are incongruent with other related studies regardless of the Dirini not included herein. Our results recover their relationships as Amathusiini $+($ Zetherini $+($ Elymniini + Melanitini $))$; whereas other related studies concluded the following relationships: (Elymniini + Melanitini) $+($ Zetherini + Amathusiini) in both ML and BI analyses of Wahlberg et al. (2009), the Elymniini + Melanitini + Zetherini + Amathusiini in MP analysis of Wahlberg et al. (2009), and the Melanitini + (Zetherini + (Elymniini + Amathusiini $))$ in BI analysis of Peńa and Wahlberg (2008). Although ribosomal genes were used for the first time in our study, and both the ML and BI trees based on the full six-gene-dataset show identical topology, it should be noticed that the nodes in ML analysis describing the tribe level relationships are lowly- or moderately-supported. Therefore, the relationships among the related five tribes recovered herein need further verification based on more sampling taxa.

The monotypic genus Callarge is distributed restrictedly in China and on the northern border of Vietnam. Morphologically, this genus has marked black veins and lacks eyespots on wings. It is currently placed in Zetherini of Satyrinae (Chou 1999; Yuan et al. 2008) by the presence of hairless eyes, the wings without striking eyespots, and the forewing with basal part of vein Sc, posterior vein of discal cell and vein $2 \mathrm{~A}$ not swollen (Chou 1998). For the first time, we verify the status of the genus based on molecular phylogenetic analyses, and reveal that it is sister to the Penthema in the present study.

\section{Acknowledgements}

We express our sincere thanks to John Richard Schrock, Emporia State University, Emporia, USA for revising the manuscript. This research is supported by the Ministry of Science and Technology of the People's Republic of China (2011FY120200, 2006FY120100).

\section{References}

Aagesen L (2004) The information content of an ambiguously alignable region, a case study of the trnL intron from the Rhamnaceae. Organisms Diversity \& Evolution 4: 35-49. doi: 10.1016/j.ode.2003.11.003

Ackery PR, de Jong R, Vane-Wright RI (1999) The butterflies: Hedyloidea, Hesperoidea and Papilionoidea. In: Kristensen NP (Ed.) Lepidoptera: moths and butterflies, 1. Evolution Systematics and Biogeography. Handbook of Zoology. Vol. IV. Part 35. Walter de Gruyter, Berlin, 263-300. 
Akaike H (1974) A new look at the statistical model identification. IEEE Transactions on Automatic Control 19: 716-723. doi: 10.1109/TAC.1974.1100705

Caterino MS, Cho S, Sperling FAH (2000) The current state of insect molecular systematics: a thriving tower of Babel. Annual Review of Entomology 45: 1-54. doi: 10.1146/annurev. ento.45.1.1

Caterino MS, Sperling FAH (1999) Papilio phylogeny based on mitochondrial cytochrome oxidase I and II genes. Molecular Phylogenetics and Evolution 11: 122-137. doi: 10.1006/ mpev. 1998.0549

Chou I (1998) Classification and identification of Chinese butterflies. Henan Scientific and Technological Publishing House, Zhengzhou, 439 pp.

Chou I (1999) Monograph of Chinese Butterflies, First Volume (Revised Edition). Henan Scientific and Technological Publishing House, Zhengzhou, 408 pp.

Danforth B, Lin C-P, Fang J (2005) How do insect nuclear ribosomal genes compare to protein-coding genes in phylogenetic utility and nucleotide substitution patterns? Systematic Entomology 30: 549-562. doi: 10.1111/j.1365-3113.2005.00305.x

Darriba D, Taboada GL, Doallo R, Posada D (2012) jModelTest 2: more models, new heuristics and parallel computing. Nature Methods 9: 772. doi: 10.1038/nmeth.2109

Drummond AJ, Suchard MA, Xie D, Rambaut A (2012) Bayesian phylogenetics with BEAUti and the BEAST 1.7. Molecular Biology and Evolution 29: 1969-1973. doi: 10.1093/molbev/ mss075

Folmer O, Black M, Hoeh W, Lutz R, Vrijenhoek R (1994) DNA primers for amplification of mitochondrial cytochrome oxidase subunit I from diverse metazoan invertebrates. Molecular Marine Biology and Biotechnology 3: 294-299.

Freitas AVL, Brown Jr KS (2004) Phylogeny of the Nymphalidae (Lepidoptera). Systematic Biology 53: 363-383. doi: 10.1080/10635150490445670

Jiang W, Zhu J, Song C, Li X, Yang Y, Yu W (2013) Molecular phylogeny of the butterfly genus Polytremis (Hesperiidae, Hesperiinae, Baorini) in China. PLoS ONE 8: e84098. doi: 10.1371/journal.pone.0084098

Katoh K, Standley DM (2013) MAFFT multiple sequence alignment software version 7: improvements in performance and usability. Molecular Biology and Evolution 30: 772-780. doi: $10.1093 / \mathrm{molbev} / \mathrm{mst} 010$

Kim MI, Wan X, Kim MJ, Jeong HC, Ahn NH, Kim KG, Han YS, Kim I (2010) Phylogenetic relationships of true butterflies (Lepidoptera: Papilionoidea) inferred from COI, 16S rRNA and EF-1 $\alpha$ sequences. Molecules and Cells 30: 409-425. doi: 10.1007/s10059-010-0141-9

Lanfear R, Calcott B, Ho SYW, Guindon S (2012) Partitionfinder: combined selection of partitioning schemes and substitution models for phylogenetic analyses. Molecular Biology and Evolution 29: 1695-1701. doi: 10.1093/molbev/mss020

Lin C-P, Danforth BN (2004) How do insect nuclear and mitochondrial gene substitution patterns differ? Insights from Bayesian analyses of combined datasets. Molecular Phylogenetics and Evolution 30: 686-702. doi: 10.1016/S1055-7903(03)00241-0

Lopez-Giraldez F, Townsend JP (2011) PhyDesign: an online application for profiling phylogenetic informativeness. BMC Evolutionary Biology 11: 152. doi: 10.1186/1471-2148-11-152 
Marín MA, Peña C, Freitas AVL, Wahlberg N, Uribe SI (2011) From the phylogeny of the Satyrinae butterflies to the systematics of Euptychiina (Lepidoptera: Nymphalidae): History, progress and prospects. Neotropical Entomology 40: 1-13. doi: 10.1590/S1519566X2011000100001

Monteiro A, Pierce NE (2001) Phylogeny of Bicyclus (Lepidoptera: Nymphalidae) inferred from COI, COII and EF-1a gene sequence. Molecular Phylogenetics and Evolution 18: 264-281. doi: 10.1006/mpev.2000.0872

Nazari V, Zakharov EV, Sperling FAH (2007) Phylogeny, historical biogeography, and taxonomic ranking of Parnassiinae (Lepidoptera, Papilionidae) based on morphology and seven genes. Molecular Phylogenetics and Evolution 42: 131-156. doi: 10.1016/j. ympev.2006.06.022

Owen CL, Marshall DC, Hill KBR, Simon C (2014) The phylogenetic utility of acetyltransferase (ARD1) and glutaminyl tRNA synthetase (QtRNA) for reconstructing Cenozoic relationships as exemplified by the large Australian cicada Pauropsalta generic complex. Molecular Phylogenetics and Evolution. doi: 10.1016/j.ympev.2014.07.008

Peńa C, Nylin S, Freitas AVL (2006) Higher level phylogeny of Satyrinae butterflies (Lepidoptera: Nymphalidae) based on DNA sequence data. Molecular Phylogenetics and Evolution 40: 29-49. doi: 10.1016/j.ympev.2006.02.007

Peña C, Wahlberg N (2008) Prehistorical climate change increased diversification of a group of butterflies. Biology Letters 4: 274-278. doi: 10.1098/rsbl.2008.0062

Price BW, Villet MH, Walton SM, Barker NP (2011) Using molecules and morphology to infer the phylogenetic relationships and evolutionary history of the Dirini (Nymphalidae: Satyrinae), a tribe of butterflies endemic to Southern Africa. Systematic Entomology 36: 300-316. doi: 10.1111/j.1365-3113.2010.00560.x

Redelings BD, Suchard MA (2009) Robust inferences from ambiguous alignments. In: Rosenberg M (Ed.) Sequence Alignment: Methods, Concepts, and Strategies. University of California Press, Berkeley, 209-270.

Ronquist F, Huelsenbeck JP (2003) MrBayes3: Bayesian phylogenetic inference under mixed models. Bioinformatics 19: 1572-1574. doi: 10.1093/bioinformatics/btg180

Silvestro D, Michalak I (2012) raxmlGUI: a graphical front-end for RAxML. Organisms Diversity \& Evolution 12: 335-337. doi: 10.1007/s13127-011-0056-0

Simon C, Buckley TR, Frati F, Stewart JB, Beckenbach AT (2006) Incorporating molecular evolution into phylogenetic analysis, and a new compilation of conserved polymerase chain reaction primers for animal mitochondrial DNA. Annual Review of Ecology, Evolution, and Systematics 37: 545-579. doi: 10.1146/annurev.ecolsys.37.091305.110018

Simon C, Frati F, Beckenbach A, Crespi B, Liu H, Flook P (1994) Evolution, weighing and phylogenetic utility of mitochondrial gene sequences and compilation of conserved polymerase chain reaction primers. Annals of the Entomological Society of America 87: 651701. doi: 10.1093/aesa/87.6.651

Stamatakis A (2006) RAxML-VI-HPC: maximum likelihood-based phylogenetic analyses with thousands of taxa and mixed models. Bioinformatics 22: 2688-2690. doi: 10.1093/bioinformatics/btl446 
Swofford DL (2002) PAUP*: Phylogenetic Analysis Using Parsimony (* and Other Methods). Sinauer Associates, Sunderland, Massachusetts.

Tamura K, Stecher G, Peterson D, Filipski A, Kumar S (2013) MEGA6: Molecular Evolutionary Genetics Analysis Version 6.0. Molecular Biology and Evolution 30: 2725-2729. doi: $10.1093 / \mathrm{molbev} / \mathrm{mst} 197$

Townsend JP (2007) Profiling phylogenetic informativeness. Systematic Biology 56: 222-231. doi: 10.1080/10635150701311362

Wahlberg N, Leneveu J, Kodandaramaiah U, Peña C, Nylin S, Freitas AVL, Brower AVZ (2009) Nymphalid butterflies diversify following near demise at the Cretaceous/Tertiary boundary. Proceedings of the Royal Society B: Biological Science 276: 4295-4302. doi: 10.1098/rspb.2009.1303

Wan J, Kim MJ, Cho Y, Jun J, Jeong HC, Lee KY, Kim I (2013) Sequence divergence and phylogenetic investigation of the Nymphalidae (Lepidoptera: Papilionoidea) occurring in South Korea. International Journal of Industrial Entomology 26: 95-112. doi: 10.7852/ ijie.2013.26.2.95

Whiting MF (2002) Mecoptera is paraphyletic: multiple genes and phylogeny of Mecoptera and Siphonaptera. Zoologica Scripta 31: 93-104. doi: 10.1046/j.0300-3256.2001.00095.x

Xia X (2013) DAMBE5: a comprehensive software package for data analysis in molecular biology and evolution. Molecular Biology and Evolution 30: 1720-1728. doi: 10.1093/ molbev/mst064

Xia X, Lemey P (2009) Assessing substitution saturation with DAMBE. In: Lemey P, Salemi M, Vandamme AM (Eds) The Phylogenetic Handbook: A Practical Approach to Phylogenetic Analysis and Hypothesis Testing, Second Edition. Cambridge University Press, Cambridge, UK, 615-630. doi: 10.1017/CBO9780511819049.022

Xia X, Xie Z, Salemi M, Chen L, Wang Y (2003) An index of substitution saturation and its application. Molecular Phylogenetics and Evolution 26: 1-7. doi: 10.1016/S10557903(02)00326-3

Yuan F, Shi H, Li Y, Shen A (2008) Taxonomic study of genus Callarge Leech, [1892] in China (Lepidoptera: Nymphalidae: Satyrinae). Sichuan Journal of Zoology 27: 725-727.

Zahiri R, Kitching IJ, Lafontaine JD, Mutanen M, Kaila L, Holloway JD, Wahlberg N (2011) A new molecular phylogeny offers hope for a stable family level classification of the Noctuoidea (Lepidoptera). Zoologica Scripta 40: 158-173. 